\title{
O uso de algoritmos para determinação de investimentos rentáveis
}

\author{
Paulo Otávio O. dos Santos ${ }^{1}$ \\ Adriana C. Omena Santos ${ }^{2}$
}

\begin{abstract}
Resumo
O presente artigo apresenta reflexões acerca da importância do uso de algoritmos na atualidade e demonstra até que ponto o uso destes na compra e venda de ações financeiras é benéfico para análise de mercado e determinação de investimentos rentáveis. Com a intenção de investigar os principais usos de algoritmos na vida em sociedade, e após pesquisa documental e bibliográfica sobre a temática, os resultados indicaram que o uso é crescente e muito maior do que o imaginado e que como a ferramenta é programada por humanos e o código programado do algoritmo limita seu universo de informações que a depender dos parâmetros poderia ter melhor uso.
\end{abstract}

Palavras-chave - algoritmos, bolsa de valores, investimentos

\section{Introdução}

A aplicação de algoritmos, sequência de instruções lógicas afim de solucionar determinado problema, é tão antiga quanto a própria matemática. Com o passar do tempo eles foram muito negligenciados como uma ferramenta útil para solução de problema, situação tal que foi revertida com a criação das calculadoras e seus subsequentes sucessores (IEPSEN, s.d.). Os algoritmos quando aplicados a essas maquinas, em especial o computador, demonstravam uma melhor eficácia na solução de grande parte dos problemas matemáticos que o próprio criador do dito algoritmo. Exatamente devido a esta eficácia tal ferramenta é utilizada em inúmeras atividades na sociedade atual, inclusive no mercado financeiro e na operação das bolsas de valores.

As bolsas de valores são mercados onde são negociadas ações, títulos que representam uma parcela do capital da empresa. A primeira delas surge em Bruges no ano de 1487 e, posteriormente, foi criada a bolsa de Antuérpia em 1531 que foi baseada na negociação de empréstimos, sendo esta considerada a primeira bolsa de valores oficial (BARROS, 2009). O autor afirma que a bolsa de valores brasileira só veio a surgir consideravelmente mais tardiamente, no Rio de janeiro em 1845.

1 Discente no curso de Gestão da Informação na Universidade Federal de Uberlândia. e-mail poos2605@hotmail.com

2 Doutora em Ciências da Comunicação, Orientadora do artigo no Programa Prossiga UFU e tutora do PET

Conexões de Saberes - Educomunicação na Universidade Federal de Uberlândia. e-mail: adriomena@gmail.com. 
O investimento nas bolsas de valores sempre foi considerado de risco, ou seja, o indivíduo que decide investir corre o risco de o investimento não gerar lucro, muitas vezes produzindo o efeito contrário, gerando prejuízo. Tal fator diminui conforme o investidor estuda o mercado e a empresa na qual pretende aplicar seu capital, porém mesmo deste modo ainda há fatores difíceis de se prever que podem vir a fazer com que a ação escolhida se desvalorize e a aplicação não seja lucrativa.

Os algoritmos entram nesse cenário de compra e venda de ações para facilitar o trabalho humano, tomar decisões mais lógicas e consequentemente procurar os melhores investimentos com base na análise do mercado fundamentada em diversos modelos econômicos e matemáticos, diminuindo assim a imprevisibilidade do investimento e calculando a probabilidade de a aplicação ser rentável ou não.

Cabe ressaltar, contudo, que a soberania dos algoritmos inteligentes na tomada de decisões não é plena. Como exemplo pode-se citar o fato de que enquanto algumas seletas pessoas conseguiram prever a chegada da crise financeira de 2008 que atingiu proporções globais usando suas projeções. Em tal situação nenhum dos algoritmos inteligentes, que aprendem com as novas informações e fazem as compras e vendas sem necessidade de ação humana, conseguiu fazer o mesmo, fato comprovado pela proporção que o evento tomou por não haver previsão de crise futura precedente ao desencadeamento da mesma.

Diante do exposto até o momento é que se sustenta a hipótese, a ser utilizada e referendada pelo artigo, de que caso o algoritmo não consiga diminuir a imprevisibilidade do problema a partir da análise de mercado, o ser humano faz uma melhor tomada decisão e antecipa melhor a situação do que a ferramenta.

\section{Algoritmos e seus usos na sociedade: estudos sobre investimentos}

Os algoritmos são parte da solução de problemas nas mais diversas áreas da sociedade muito antes da criação de maquinas capazes de otimizar o uso dos mesmos. Como Terzidis (2006 apud A. SILVA JR., 2011, p.66) explica, o uso dos mesmos não está condicionado a ser aplicado em algumas dessas maquinas, em especial o computador. Para o autor,

A utilização do algoritmo não está limitada ou condicionada ao uso do computador. Na realidade a arquitetura tem feito uso desse tipo de gerenciamento de dados mesmo antes da invenção do computador. As 
regras e instruções, utilizadas para definir um templo grego ou as Vilas de Palladio em sua essência são algoritmos. Desse modo a invenção das maquinas veio incrementar a aplicação dessas práticas. (TERZIDIS, 2006, p.17 apud A. SILVA JR., 2011, p.66)

Embora a sua aplicação à problemas possa vir a ser benéfica para o usuário, há limitações, afinal dado o fato de que como sendo uma série de instruções lógicas definidas pelo seu criador afim de solucionar ou ajudar a solucionar determinado problema, a ferramenta é somente tão boa quanto a capacidade de seu criador de criar e estruturar tais instruções.

As instruções que compõem os algoritmos podem ser identificadas pelo seu uso na arquitetura, pois segundo Frazer (1995, p. 58 apud SILVA JR, 2011, p.66):

O uso de algoritmos na arquitetura consiste em ganho significativo para o processo projetivo. Os algoritmos possuem um potencial generativo que possibilita o surgimento de soluções inesperadas para uma dada questão. Além disso, eles são capazes de apresentar respostas satisfatórias para problemas que não estão completamente definidos.

A partir de qual ponto o uso de algoritmos é mais benéfico para solução, prevenção e previsão de problemas ainda é incerto, considerando que não compreendemos muito bem porque em algumas áreas ele é melhor e em outras não. Para exemplificar é possível observar, por exemplo, o seu uso na bolsa de valores, que vem sendo muito aplicado e mostra resultados melhores que o de humanos na tomada de decisões. Cabe lembrar que "a eficácia dessa ferramenta na bolsa de valores é tão alta que os algoritmos já superaram os humanos na bolsa de valores” (ATAQUE, 2015, s. p.).

A operação em bolsa de valores apresenta um alto nível de imprevisibilidade, diversos modelos matemáticos e teorias foram desenvolvidos visando minimizar essa imprevisibilidade e por consequência maximizar o lucro de investimentos nessa área, porem a maioria foi sem sucesso. Mesmo em tal quadro surge na atualidade outro modelo conhecido como a Teoria moderna do portfólio, derivada da teoria do portfólio de Harry Markowitz que criou o conceito de risco-retorno. De acordo com Souza (1999, p.1)

A Teoria do Portfólio de Harry Markowitz discorre sobre maximização do retomo esperado de acordo aos níveis de aceitação do investidor 
perante o risco envolvido. De acordo com MARKOWITZ (1952), o processo de escolha' de um portfólio divide-se em duas partes: primeiro, começa com observação e experiência do administrador de fundos e termina com crenças sobre a avaliação da performance futura; segundo, parte das crenças relevantes sobre a performance futura e termina com a escolha do portfólio".

O autor defende que o objetivo geral da Teoria se refere ao gerenciamento de carteiras de investimentos, utilizando a seleção de portfólios afim de maximizar o retorno levando em consideração um nível de risco. É defendido também que para que o portfólio seja construído com eficiência o investidor deve selecionar dentre os investimentos com mesmo retorno, aquele que tiver o menor risco.

O autor segue sua explanação afirmando que a teoria de Markowitz também leva em consideração a diversificação de investimentos de forma a alocar os recursos do investidor em diferentes ativos. Dado a incerteza do mercado de ações, é difundido atualmente a diversificação de investimentos afim de minimizar o prejuízo e maximizar o lucro, usando para isso o conceito de risco-retorno de Markowitz, que pressupõem escolher o investimento com menos risco e com mesmo ou maior retorno.

O autor prossegue ainda explicando que Markowitz não necessariamente classifica a diversificação como sendo melhor que a não diversificação, ele apenas simplesmente explica que com ela é possível que haja diminuição do risco no investimento. E assimila o fato de os investimentos diversificados estarem ligados à crise asiática.

Mas a que se deve essa imprevisibilidade é incerto ainda, há teorias, porém, que dizem que não é somente aos fatores internos ao mercado e sim uma junção dos indicadores internos e externos, como por exemplo, emoções e humor da população.

Acerca de tal assunto cabem as considerações de Bollen (2010, p.1) quando afirma que

A partir de uma pesquisa psicológica nós sabemos que emoções, juntamente com informação, desempenham um papel significativo na tomada de decisões. O comportamento financeiro proporcionou ainda mais provas que as decisões financeiras de uma pessoa são consideravelmente dirigidas por emoções e humor. Logo é razoável assumir que o humor público e sentimentos podem influenciar a bolsa de valores no mesmo nível que noticias o influenciam.

Para o autor os preços passados e atual do mercado não é o fator que mais influência o futuro valor que será dado a determinada ação, esse papel é desempenhado 
pelas notícias. Bollen diz ainda que como as notícias são imprevisíveis é extremamente difícil fazer uma previsão do mercado com precisão maior que 50\%. Afirma, ainda, que “apesar das notícias com certeza influenciarem o Mercado de ações, o humor público ou sentimento podem ter a mesma influência.”

De maneira geral pode-se afirmar que a bolsa de valores é um mercado que como tudo, está repleto de padrões, a dita imprevisibilidade é simplesmente a limitação do ser humano em trabalhar com grande quantidade de dados e não somente na limitação em enxergar os padrões na bolsa de valores, uma vez que

Entende-se por padrão as propriedades que possibilitam o agrupamento de objetos semelhantes dentro de uma determinada classe ou categoria, mediante a interpretação de dados de entrada, que permitam a extração das características relevantes desses objetos, (Tou e Gonzáles, 1981). Entende-se por classe de um padrão um conjunto de atributos comuns aos objetos de estudo. Assim, reconhecimento de padrões pode ser definido como sendo um procedimento em que se busca a identificação de certas estruturas nos dados de entrada em comparação a estruturas conhecidas e sua posterior classificação dentro de categorias, de modo que o grau de associação seja maior entre estruturas de mesma categoria e menor entre as categorias de estruturas diferentes (MONTEIRO DE CASTRO, 1999-2002, p.2).

O autor afirma, ainda que os serem humanos são exímios quando se trata no reconhecimento de padrões, podendo estes padrões serem por exemplo rostos, vozes, caligrafias e estados de humor de pessoas conhecidas. Explica, também, que tal habilidade nos humanos com o devido treinamento pode chegar ao ponto de distinguir pinturas originais feitas por um grande artista das demais falsificações ou na tomada de decisões de um trabalhador em um dia movimentado no mercado de ações.

Castro (1999-2002, p.2) ainda explica o que são padrões, classes e o reconhecimento dos ditos padrões ao afirmar que

[...] pode-se dizer que padrões são os meios pelos quais o mundo é interpretado e, a partir dessa interpretação, elaboram-se atitudes e decisões. Percebe-se, também, que nos exemplos citados, tal facilidade no reconhecimento de padrões está diretamente vinculada aos estímulos aos quais o indivíduo foi exposto anteriormente. Isso leva a supor que a estrutura selecionada pela evolução biológica para desempenhar bem a tarefa de reconhecimento de padrões incorpora alguma forma de aprendizado e evolui com a experiência. O grande desafio proposto neste início de século é o de desenvolver máquinas que tenham tais comportamentos. 
É então que são aplicados os algoritmos inteligentes, capazes de adquirir nova informação e trabalhar com ela, para captar uma grande quantidade de informação de mercado e organizá-la afim de achar um padrão de mercado e solucionar o problema de saber onde investir o dinheiro

Ainda no século passado Frank, Baker e Herron (1987) já discorriam sobre a solução de problemas em seu trabalho sobre o uso de algoritmos para a solução de problemas. No trabalho em questão os autores citam o escritor John Hayes que define a solução de problemas como um processo que envolve duas condições a serem analisadas. A primeira sendo que deve haver um obstáculo entre onde você se encontra atualmente e onde está o seu objetivo.

O texto supracitado indica que posteriormente há uma segunda condição e não pode haver um caminho obvio para transpor esse obstáculo. Se a determinada situação em que está sendo trabalhada atende a estes dois critérios somente então para Hayes o que está sendo trabalhado é um problema e não somente um exercício. Os autores discorrem, ainda, sobre as tarefas que são aplicadas aos estudantes, que comumente são chamadas de exercícios e explicam que o método para resolução destas tarefas é mais simples que a solução de um problema.

Segundo os autores a solução de um exercício é dada normalmente pela identificação e aplicação de algum algoritmo, que na praxe já é existente, pois o algoritmo em si levará a uma solução. Cabe ressaltar, porém, que problemas são mais complicados, o uso de algoritmos como solução absoluta não é funcional como no caso de suas aplicações em meros exercícios. Para resolver problemas, segundo os autores, é preciso que haja primeiro etapas para estruturar o problema para achar o melhor caminho para percorre-lo para que somente depois então comece a pensar se é necessário o uso de algoritmos ou se eles ajudariam de alguma forma para completar o objetivo em questão. Segundo os autores,

Se a primeira resposta de uma pessoa à algum problema é decidir qual algoritmo usar, então o indivíduo não está solucionando o problema. Porém se a pessoa usa um algoritmo como uma etapa da resolução somente, modifica um algoritmo ou cria um novo, então ela está realmente fazendo um uso eficiente de algoritmos na solução de problemas. (FRANK, BAKER, HERRON, 1984, p.2). 
Outro ponto que pode ser considerado é que como a bolsa de valores é um mercado de previsões e os algoritmos têm excedido a capacidade humana, porém algoritmos são instruções lógicas e matemáticas. Logo não conseguem prever a emoção humana que também afeta o mercado. Assim, é especulado que seja por isso que em certos pontos onde a maioria dos algoritmos falham a capacidade humana se excede, pois, a ferramenta não consegue interpretar emoções e as pessoas conseguem. Logo ao contrário de como é mais aplicado atualmente, ou somente decisão humana ou somente o uso de algoritmos, deve-se ser utilizado no mercado de ações uma junção dos dois, ferramenta humana e ferramenta matemática.

\section{Procedimentos, resultados e discussões}

Para o desenvolvimento do trabalho foi realizada a revisão bibliográfica sobre o uso dos algoritmos na sociedade em geral e, em particular, nas aplicações das bolsas de valores. A consulta envolveu uma busca em 18 dissertações, teses, artigos e demais documentos acerca do assunto. Após leitura e fichamento dos trabalhos foram selecionados aqueles discorrem sobre o uso dos algoritmos, mercado financeiro, bolsa de valores, comportamento humano e variáveis na tomada de decisões financeira e como o humor das pessoas e notícias afetam o valor das ações na bolsa.

Trata-se, portanto, de uma pesquisa com viés exploratório e descritivo tendo em vista o assunto abordado. Utilizou-se a descrição do material consultado para discorrer acerca da eficácia ou não do uso dessa determinada ferramenta. O método utilizado foi o hipotético dedutivo, pois como já exposto partiu-se da hipótese de que embora os algoritmos sejam mais eficientes que humanos no reconhecimento de padrões e análise de grande quantidade de dados, há informações que essa ferramenta não explora da melhor forma possível. Informações tais que influenciam também o mercado e podem vir a explicar como no lugar em que algoritmos falham na previsão, humanos se excedem, como na previsão de mercado a partir da análise de sentimentos e humor das pessoas.

Assim, discorreu-se o tema utilizando os trabalhos lidos visando proporcionar um embasamento suficiente para a formação da teoria de que algoritmos são melhores aplicados quando em junção de ação humana a partir da hipótese apresentada anteriormente. 
Tendo com embasamento a fundamentação teórica decorrente do levantamento bibliográfico é possível apresentar como exemplo o conflito da eficácia do uso de algoritmos no mercado financeiro a partir do caso do físico americano Michael Burry. O físico conseguiu prever a crise no mercado imobiliário dos EUA, derivada da venda de títulos de hipoteca, 3 anos antes e investir previamente com base nas informações descobertas. Tal ação permitiu um desdobramento que gerou lucro de aproximadamente 489\% para a Scion Capital, fundo de investimento criado por ele no ano 2000. Sua iniciativa confrontou a visão de esmagadora parte dos investidores e os algoritmos inteligentes aplicados nessa área apontando que o mercado imobiliário dos EUA era sólido.

Assim, como é explicado por Castro e Prado (1999-2002), no texto sobre o uso de algoritmos, os serem humanos são exímios em identificar padrões, mas ao contrário dos algoritmos, que são limitados pelo universo de dados que estão programados para analisar, pode visualizar a situação como um todo. Foi assim que o físico Burry previu a crise. Analisou, e aplicou à atualidade, que na crise imobiliária de 1930, que fez com que aproximadamente $80 \%$ do mercado nessa área entrasse em colapso, houve indicadores anteriores à mesma, como o aumento dos níveis de complexidade e de fraude nos empréstimos hipotecários tanto por parte dos credores tanto por parte dos devedores.

Michael Burry enxergou esses padrões e começou a investir contra o mercado de imóveis através da compra de ações utilizando o mercado a termo. Mercado a termo é a compra de determinado número de partes da sociedade de uma empresa que será paga não a vista, mas após determinado tempo estipulado em contrato, após o vencimento do prazo o credor recebe o dinheiro das ações com base na cotação de quando foi assinado o acordo com o adicional de uma taxa de juros previamente acordada.

Após o estouro da crise, o físico lucrou acima das expectativas ao mesmo tempo em que o mercado no país inteiro declinava e diversos bancos faliam. Existe um ponto a ser discutido sobre o ocorrido com Michael Burry e a crise, que é entender como e porque os algoritmos inteligentes, que adquirem novas informações e conseguem trabalham com ela automaticamente, falharam em prever o que o físico conseguiu observar. Pode ser afirmado que simplesmente foi mais uma vez o ser humano superando as maquinas, mas a realidade é que ao analisar profundamente, o erro dos 
algoritmos é derivado do erro humano e que afetou o restante da população que não previu o evento catastrófico.

Fato importante é que a maior parte das pessoas que não enxergou o colapso iminente fizeram-no devido às informações falsas que recebiam de que os empréstimos de hipotecas poderiam ser renegociados e que o mercado imobiliário era solido. Tais informações geraram um sentimento de conforto e segurança, sentimento esse que afetou também os investidores que assumiram a estabilidade do mercado como certa e não tendo a inciativa e o cuidado de checar se os investimentos eram ou não realmente sólidos.

Como são os humanos que desenvolvem os algoritmos, a ferramenta exerce somente o que é escrito em seu código. Assim, os desenvolvedores do programa de análise de dados financeiros, incluindo a área imobiliária, como se sentiam totalmente seguros do investimento não configuraram o algoritmo para analisar o mercado e padrões. Tal situação tornou-se terreno fértil para um colapso, comprovado facilmente pela falta de identificação desses padrões por parte da tecnologia e de grande parte da população.

Mudando o foco para o macro mercado de ações, e não somente no setor imobiliário, é de conhecimento que previsões sobre a bolsa de valores atingem historicamente um máximo de 50\% de precisão, conforme descrito por Johan Bollen (2010). Em tal contexto, e com base na análise da situação previamente citada é possível afirmar que os algoritmos são somente tão bons quanto as habilidades do criador de o programar para abranger um maior universo de informações e padrões. Ou seja, é possível compreender o porquê essas ferramentas matemáticas são bastante eficazes no mercado financeiro e as vezes falham completamente.

Os algoritmos são melhores que humanos no reconhecimento de padrões, pois conseguem gerir uma enorme quantidade de dados em pouco tempo a uma taxa humanamente impossível. Contudo, mesmo os algoritmos inteligentes não conseguiram prever a crise e falharam devido ao fato de que nenhum deles foi programado com as informações necessárias ou que captassem estas no mercado. Tais informações são os indicadores que o físico Michael Burry enxergou e foram vistas antes somente na crise imobiliária de 1930. Como a ferramenta não possuía essa informação em seu código, e nem a capacidade de observá-la, quando houve uma repetição do padrão, ela não soube reconhecer para remover os investimentos do mercado de imóveis. Situação semelhante 
ocorre com as pessoas, os algoritmos são somente melhores no mercado, pois obtém mais informações de forma mais rápida do que seres humanos.

A falha em cada um dos investidores, algoritmos ou humanos, não se trata de sorte ou área de aplicação e sim da quantidade de informações disponíveis a cada um deles. Se disponibilizarmos a mesma quantidade de informação a um humano e a um algoritmo, o posterior terá vantagem pois a decisão lógica será tomada mais rapidamente devido ao processamento do computador ser superior ao cérebro humano, mas não em sua capacidade e criatividade.

Como a competência ou não do algoritmo é diretamente proporcional a quantidade de informações úteis disponíveis ao ocorrer certas condições é possível que pessoas superem essa tecnologia. O primeiro caso seria se a ferramenta não for apta para analisar como as informações disponíveis afetarão o mercado, logo as informações não serão uteis, pois não poderão ser usadas para tomada de decisão lógica. A segunda ocorrência é quando o algoritmo possui menos informações uteis que o investidor humano, assim sendo, terá menos dados para tomar a melhor decisão possível que foi o que ocorreu em 2008.

\section{Considerações finais}

Acerca do uso de algoritmos inteligentes no mercado de ações é possível destacar-se os pontos mais importantes. A obra de Bollen (2010) que busca explicar, como o humor individual e coletivo, afetam a bolsa de valores. Essas informações se tornam de difícil interpretação para os algoritmos algumas vezes. Há também a teoria do portfólio de Markowitz (1952) usada amplamente nas diversas áreas de investimentos. Com base nas obras analisadas é possível concluir que a hipótese inicial proposta neste artigo de que, caso o algoritmo não consiga diminuir a imprevisibilidade do problema, o ser humano fará uma tomada de decisão melhor, é falsa. Porém juntamente com a refutação da hipótese inicial há a sugestão de uma nova proposta baseada nas informações adquiridas. Este artigo propõe ainda, que no final o triunfo ou não dos algoritmos na área de mercado financeiro é função de um outro fator: a falha humana.

Por fim, como conclusão final afirma-se que como a ferramenta é programada por humanos e o código programado do algoritmo limita seu universo de informações. Quando ocorre de ser programada de forma limitada, no que tange a observação de 
todos os parâmetros do problema, o ser humano terá acesso a mais informações e nesse caso desempenhará um papel melhor. Do contrário, quando o algoritmo tem informações em quantidade iguais ou superiores ao do ser humano, a decisão tomada será mais lógica e consequentemente aumentará a chance de o investimento ser lucrativo. 


\section{Referencias}

ATAQUE, Ataque das máquinas: algoritmos superam humanos na bolsa. Infomoney. São Paulo, SP: Money \& Markets Editora, 2015.

BARROS, R. O que faz e como surgiu a bolsa de valores?. Nova Escola V.228. São Paulo, SP: Editora Abril, 2009.

BOLLEN, J.; M.; H.; and Zeng, X. J. Twitter mood predicts the stock market. Journal of Computational Science 2(1). Manchester, UK: 2009, p.1-8.

FRANK, D.V; BAKER, C.A; HERRON; J.D. Should Students Always Use Algorithms To Solve Problems?. Journal of chemical education V.64. US: Division of Chemical Education of the American Chemical Society, 1987, p.514-515.

CASTRO, A.A. M.; PADRO, P.P. l. Algoritmos para reconhecimento de padrões. Rev. Ciênc. Exatas V.5-8. Taubaté, SP: UNITAU, 1999-2002, p.129-145.

SILVA JÚNIOR, Félix Alves da. O uso de algoritmos e de sistemas paramétricos na concepção arquitetônica de pequenas residências. 2011. xii, 131 f. Dissertação (Mestrado em Arquitetura e Urbanismo)-Universidade de Brasília, 2011.

SOUZA, Z. J.; BIGNOTTO, E. C. Teoria de Portfolio: Composição Ótima de uma Carteira de Investimento. Econ. Pesqui V. 1, N. 1. Araçatuba, SP:, 1999, p. 61-78. 